\title{
Editorial: Optimizing the Delivery of Multiple Ecosystem Goods and Services in Agricultural Systems
}

\author{
Maria A. Tsiafouli ${ }^{1 *}$, Evangelia G. Drakou ${ }^{2}$, Alberto Orgiazzi ${ }^{3}$, Katarina Hedlund $^{4}$ and \\ Karl Ritz ${ }^{5}$ \\ ${ }^{1}$ Department of Ecology, School of Biology, Aristotle University of Thessaloniki, Thessaloniki, Greece, ${ }^{2}$ Faculty of \\ Geo-Information Science and Earth Observation (ITC), University of Twente, Enschede, Netherlands, ${ }^{3}$ Land Resources Unit, \\ Joint Research Centre, Directorate for Sustainable Resources, European Commission, Ispra, Italy, ${ }^{4}$ Department of Biology, \\ Faculty of Science, Lund University, Lund, Sweden, ${ }^{5}$ Division of Agricultural and Environmental Sciences, University of \\ Nottingham, Loughborough, United Kingdom
}

Keywords: soil, soil biodiversity, pollination, scale, conceptual frameworks, perennial crops, high-value farmlands

\section{Editorial on the Research Topic}

\section{Optimizing the Delivery of Multiple Ecosystem Goods and Services in Agricultural Systems}

\section{OPEN ACCESS}

Edited and reviewed by:

P. K. Ramachandran Nair, University of Florida, United States

*Correspondence: Maria A. Tsiafoul tsiafoul@bio.auth.gr

Specialty section:

This article was submitted to Agroecology and Land Use Systems,

a section of the journal

Frontiers in Ecology and Evolution

Received: 14 July 2017

Accepted: 31 July 2017

Published: 15 August 2017

Citation:

Tsiafouli MA, Drakou EG, Orgiazzi A, Hedlund K and Ritz K (2017) Editorial: Optimizing the Delivery of Multiple

Ecosystem Goods and Services in Agricultural Systems.

Front. Ecol. Evol. 5:97. doi: 10.3389/fevo.2017.00097
Agricultural land is subjected to a variety of societal pressures, as demands for food, animal feed, and biomass production increase, with an added requirement to simultaneously maintain natural areas, and mitigate climatic and environmental impacts globally (Tilman et al., 2002; Pretty, 2008; Wang and Swallow, 2016). The biotic elements of agricultural systems interact with the abiotic environment to generate a number of ecosystem functions that offer services benefiting humans across many scales of time and space (Swinton et al., 2007; Power, 2010). The intensification of agriculture, particularly of that founded on fossil-fuel derived inputs, generally reduces biodiversity, including soil biodiversity (Tsiafouli et al., 2015) and impacts negatively upon a number of regulating and supporting ecosystem services (Zhang et al., 2007). There is a global need toward achieving sustainable agricultural systems, highlighted also in the UNs' Sustainable Development Goals, where among their targets they state that by 2030 we should globally "ensure sustainable food production systems and implement resilient agricultural practices that increase productivity and production, that help maintain ecosystems, that strengthen capacity for adaptation to climate change, extreme weather, drought, flooding and other disasters and that progressively improve land and soil quality" (UN-DESA/DSD, 2014).

There is hence an evident need for management regimes that enhance both agricultural production and the provision of multiple ecosystem services. The articles of this Research Topic enhance our knowledge of how management practices applied to agricultural systems affect the delivery of multiple ecosystem services and how trade-offs between provisioning, regulating, and supporting ecosystem services can be handled both above- and below-ground, and across multiple scales of space and time. They also show the diversity of topics that need to be considered within the framework of ecosystem services delivered by agricultural systems, from knowledge on basic concepts and newly-proposed frameworks $(\S 1)$, to a focus on specific ecosystem types such as grasslands and high nature-value farmlands (§2), pollinator habitats (§3), and soil habitats (§4). 


\section{CONCEPTUAL AND METHODOLOGICAL FRAMEWORKS - INTEGRATING HUMAN-INDUCED, BIOTIC, AND ABIOTIC PROCESSES ACROSS SCALES}

Although the knowledge on management practices and their impacts on the biotic and abiotic components of agricultural landscapes are widely studied, application-oriented and targeted theoretical and methodological frameworks, keep emerging (e.g., Therond et al., 2017). Such frameworks are developed and assessed across a range of spatio-temporal scales to ensure their validity. For instance, Tscharntke et al. (2005) have highlighted the importance of the landscape-scale approach to investigating effects of agricultural management practices. The series of conceptual and application-oriented articles presented in this Research Topic show how configuration of agricultural land at landscape spatial scales is linked to the optimization of ecosystem service delivery. Starting with a conceptual discussion paper, Ekroos et al. redirect the debate on what is the best practice between "land sparing" and "land sharing," to a new crossscale assessment to improve the management of transformed landscapes. They argue that in order to ensure that agricultural systems are able to maximize yields while maintaining a series of ecosystem benefits, a multiple-scale land-sparing practice is required. They propose to apply this larger scale approach either within groups of collaborating farms or at a regional level, while taking into account the trade-offs among scales.

Williams et al. in their opinion paper give an overview of the background knowledge required to apply and use soil functional zone management (SFZM) methods for more sustainable systems of agricultural production. They also present a conceptual framework that can be applied to account for the feedback loops generated in agricultural production. They claim that the SFZM method allows the sustainable management of the soil, in order to provide multiple ecosystem services directly linked to agricultural production, or indirectly supporting it. It also allows to minimize trade-offs among ecosystem services generated by soils and agricultural production. Furthermore, SFZM can lead to productivity optimization. Vinatier et al. in their perspective article propose a spatially-explicit unified conceptual framework that integrates biotic and abiotic processes and human activities. In particular, they propose a shared representation of distinct immobile and mobile (both biotic and abiotic) landscape elements, which allow understanding of complex landscape functioning by different disciplines and the setting of common objects and spatio-temporal process boundaries. Their framework develops a common view of agricultural landscapes, simplifies the representation of the complex system, but leaves the possibility to include current modeling strategies specific to biotic or abiotic disciplines.

Schulte et al. in their hypothesis and theoretical article set a Functional Land Management framework for policymaking. Within this framework demands of food security and environmental sustainability are met by incentivizing land use and soil management practices that selectively augment specific soil functions, such as provision of food, fiber and fuel, water purification and carbon sequestration, and biodiversity support, where required. Using Ireland as a case study they show that demands for contrasting soil functions may apply to very different spatial scales, and require local or regional/national scale management. For optimization they refer to 14 policy and market instruments that are available in the European Union and outline the merit in adapting existing governance instruments by facilitating differentiation between soils and landscapes.

In a concept-and-application paper, Marton et al. explain how a "contract rearing system" could be adopted for sharing labor between the labor-intensive dairy production system in the lowlands and the less-labor-intensive farming system in the mountains. This sharing of intensity helps maintain attractive landscapes (i.e., a cognitive function) and fosters their high nature value, while reducing environmental impacts of agricultural production.

\section{GRASSLANDS, PERENNIAL, AND HIGH NATURE-VALUE FARMLANDS}

The advantages of farmlands involving perennial crops and grasslands vs. annual crops is a topic of broad discussion and research over the past decade (e.g., Ferchaud et al., 2016; Miller et al., 2016; Vico et al., 2016). Several articles in this Research Topic focus on how different types of farmlands and other land uses are providing multiple long-term ecosystem services. In search of grassland vegetation restoration for preventing soil erosion and desertification, Zhang et al. investigate the results of land enclosure in the Loess Plateau of northwestern China. They demonstrate that a moderate amount of litter favors seedling emergence, whereas continually increasing litter diminishes the phenomenon. They suggest that a moderate utilization of litter can lead to moderate disturbance, which favors downward movement of seeds and accelerates vegetation restoration. They conclude that litter amount can serve as a guide for monitoring and managing grassland ecosystems, as it is an indicator of ecosystem processes that are essential for biodiversity conservation and restoration.

On perennial systems, Winkler et al. explore the multifunctional role of vineyard ecosystems as agricultural landscapes. Through a literature review, they identify that the multi-functionality of vineyards has rarely been explored or taken into account into management. They provide a detailed analysis/description of the different ecosystem services provided by vineyards and conclude that there are very few cases in which such services are considered in the management of vineyards, mostly linked to cultivated crops and sequestration. Finally, authors call for more research and practice that applies the ecosystem service approach to vineyard systems. Gardi et al. investigate soil carbon (C) storage in high nature-value farmlands of Europe. By considering soil carbon content as a proxy for storage they show that the $\mathrm{C}$ content is higher in high nature-value farmlands than in conventional ones, with the amount of $\mathrm{C}$ strongly affected by the type of land use and the geographic region. They also discuss limitations 
in the classification and mapping of agricultural systems at continental scale. In order to mitigate these limitations, they suggest first to evaluate soil $\mathrm{C}$ content at a more detailed scale as a function of different types of land/agricultural management under different environmental conditions, and then upscale the information.

\section{POLLINATOR HABITATS}

Pollination is a key ecosystem function of insects targeting pollinator-dependent plants. The pollinator-plant interaction can increase the productivity of many agricultural systems thereby contributing to societal well-being (Klein et al., 2007; Lautenbach et al., 2012; Garibaldi et al., 2014; IPBES, 2016). Four articles covering this Research Topic highlight the significance of pollination and outline ways to preserve and enhance pollinators and their habitats in different spatial scales.

Sidhu and Joshi in their opinion article suggest methods to optimize wildflower pollinator habitats in agricultural farmland to benefit from multiple ecosystem services. The authors consider factors such as complementary composition of wildflower availability and crop bloom period pollination requirements and highlight the importance of pollinator habitats establishment in simple landscapes with fragmented resources. The factors considered might hinder farmers to establish pollinator habitats. In order to increase their acceptance and use, they recommend focusing more on the role of pollinator habitats in supporting on-farm pest control, than biodiversity conservation in general. Klatt et al. in their opinion article argue how restriction of neonicotinoid insecticides in the European Union might provide benefits but also risks to bees and pollination services. As the use of pesticides is an integral part of contemporary agriculture, the authors claim that neonicotinoid restrictions will lead farmers to find suitable alternatives. Knowledge about the general impact of insecticides on pollinators is still limited, especially considering long-term effects and pollinator species others than bees. They conclude that an expanded scientific evidence base is needed to assess the risks and benefits of alternative pest management strategies.

Joshi et al. specifically explore the factors that drive pollinator visitation in apple orchards and associate it with landscape patterns in order to identify the best landscape configuration to ensure high pollination rates for apple trees. They focus on heterogeneous landscapes surrounding apple orchards, and the impact they have on the frequency of several pollinator species. From their field measurements (Pennsylvania, USA) it appears that proximity to unmanaged habitat and low degree of heterogeneity were the principal prevailing factors affecting the pollinator-visitation frequency. Finally, Parejo et al. present a genomic approach, based on molecular markers, for monitoring European honey bee subspecies and, thus, ensuring the delivery of pollination services. Their analysis prescribes a limited panel of single nucleotide polymorphisms (SNPs) which could be used for distinguishing native from non-native honey bee populations and, consequently, establishing preservation actions.

\section{SOIL AND SOIL BIODIVERSITY}

Soil ecosystem services generated from soil food webs play a key role in sustainable agricultural systems (Shennan, 2008; De Vries et al., 2013; Ferris and Tuomisto, 2015). Four articles on this Research Topic focus on agricultural practices applied to soil and soil biodiversity toward increasing multifunctionality in agro-ecosystems. Zhang et al. explore the application of a common agricultural practice in China, that of film mulching, as a way to increase water availability for crops and thus to improve production of maize. They applied five different types of mulching and estimated how each affected topsoil temperature, soil water storage and maize yield and also the corresponding economic revenues. The consecutive film-mulched ridge method proved to be the one producing the highest yield for maize fields in such semi-arid regions.

Koskey et al. examined the effectiveness of native rhizobia isolates in enhancing nitrogen fixation and yields of climbing beans in greenhouse and field experiments in Kenya. They found four native rhizobia isolates to show higher symbiotic efficiency compared to commercial inoculants in both the considered bean varieties. One of the inoculants led to up to $90 \%$ highest seed yield compared to non-inoculated control and up to $30 \%$ increase over commercial inoculants. They conclude that within the framework of enhancing delivery of agroecosystem services, such as nitrogen fixation and bean production, characterization and mapping of native isolates is imperative to develop effective and affordable commercial inoculants. This demonstrates that some strategies based upon local circumstances are likely to be more effective than those that attempt large-scale unified solutions that may require other interventions to compensate for the inherent diversity in systems at such local levels. The scale of such "locality" may also vary according to circumstances.

The need for conservation actions to support the ecosystem services provided by different arthropods is the common denominator of the manuscripts by Birkhofer et al. and de Groot et al. The former article investigates the effects of different landuse intensities on soil mites, collembolans, myriapods and the functions that they sustain in grasslands, from decomposition to control of belowground pests. The study confirms the potential of both biodiversity and food web analyses to assess the impact of human interventions on ecosystem services delivered by soil fauna. De Groot et al. examined the results of land management extensification. They specifically studied the succession of mite communities following conversion of arable land to grassland in a chronosequence representing a 29 -year long period. They found that diversity and biomass of mites steadily rose over time since the conversion. Consequently, nutrient cycling increased and the suppression of potential pests improved. They discuss the relevance of these ecosystem services in extensively managed grasslands and suggest including grasslands for one or more years in agricultural rotational schemes to ensure a better provision of the considered ecosystem services. Finally, the metaanalysis of Trivedi et al. provide evidence that conversion from natural grasslands to agriculture cause community scale trends 
of microbial biodiversity across global biomes. They propose that microbial abundance may serve as an indicator for changing soil health as it is more responsive to land use change than other physical and chemical soil factors. This knowledge can be used to facilitate decision making for soil health and soil biodiversity.

\section{CONCLUSIONS}

Collectively, the papers in this Research Topic consider very different concepts of what it takes to optimize the delivery of multiple ecosystem services in agricultural systems: they address basic concepts, encompass small to large scales, changes in time and space, soil management, and soil biodiversity to pollination. They essentially form a scientific ensemble that helps evaluate the impact of human pressures on the provision of ecosystem services and nurture the development of measures for a more sustainable management of agricultural areas. The publication of this volume comes at a key moment in which the delivery of

\section{REFERENCES}

De Vries, F. T., Thébault, E., Liiri, M., Birkhofer, K., Tsiafouli, M. A., Bjørnlund, L., et al. (2013). Soil food web properties explain ecosystem services across European land use systems. Proc. Nat. Acad. Sci. U.S.A. 110, 14296-14301. doi: 10.1073/pnas.1305198110

Ferchaud, F., Vitte, G., and Mary, B. (2016). Changes in soil carbon stocks under perennial and annual bioenergy crops. GCB Bioenergy 8, 290-306. doi: $10.1111 /$ gcbb. 12249

Ferris, H., and Tuomisto, H. (2015). Unearthing the role of biological diversity in soil health. Soil Biol. Biochem. 85, 101-109. doi: 10.1016/j.soilbio.2015.02.037

Garibaldi, L. A., Carvalheiro, L. G., Leonhardt, S. D., Aizen, M. A., Blaauw, B. R., Isaacs, R., et al. (2014). From research to action: enhancing crop yield through wild pollinators. Front. Ecol. Environ. 12, 439-447. doi: 10.1890/130330

IPBES (2016). The Assessment Report of the Intergovernmental Panel for Biodiversity and Ecosystem Services on Pollinators, Pollination and Food Production. Bonn: IPBES.

Klein, A. M., Vaissière, B. E., Cane, J. H., Steffan-Dewenter, I., Cunningham, S. A., Kremen, C., et al. (2007). Importance of pollinators in changing landscapes for world crops. Proc. R. Soc. B Biol. Sci. 274, 303-313. doi: 10.1098/rspb.2006.3721

Lautenbach, S., Seppelt, R., Liebscher, J., and Dormann, C. F. (2012). Spatial and temporal trends of global pollination benefit. PLOS ONE 7:e35954. doi: 10.1371/journal.pone.0035954

Miller, J. N., VanLoocke, A., Gomez-Casanovas, N., and Bernacchi, C. J. (2016). Candidate perennial bioenergy grasses have a higher albedo than annual row crops. GCB Bioenergy 8, 818-825. doi: 10.1111/gcbb.12291

Power, A. G. (2010). Ecosystem services and agriculture: tradeoffs and synergies. Philos. Trans. R. Soc. B Biol. Sci. 365, 2959-2971. doi: 10.1098/rstb.2010.0143

Pretty, J. (2008). Agricultural sustainability: concepts, principles and evidence. Philos. Trans. Soc. R. B. Biol. Sci. 363, 447-465. doi: 10.1098/rstb.2007.2163

Shennan, C. (2008). Biotic interactions, ecological knowledge and agriculture. Phil. Trans. R. Soc. B Biol. Sci. 363, 717-739. doi: 10.1098/rstb.2007.2180

Swinton, S. M., Lupi, F., Robertson, G. P., and Hamilton, S. K. (2007). Ecosystem services and agriculture: cultivating agricultural ecosystems for diverse benefits. Ecol. Econ. 64, 245-252. doi: 10.1016/j.ecolecon.2007.09.020

Therond, O., Duru, M., Roger-Estrade, J., and Richard, G. (2017). A new analytical framework of farming system and agriculture model diversities: a review. Agron. Sustain. Dev. 37:21. doi: 10.1007/s13593-017-0429-7 ecosystem services by agricultural systems is of high importance (IPBES, 2016) and the need to achieve the UN Sustainable Development Goals for 2030 (UN-DESA/DSD, 2014) becomes an urgent issue to be addressed. We aspire that this collective work will inform and stimulate more studies on this Research Topic the coming years. Whilst it is sometimes a cliché to state that "further research is needed....," this is certainly the case here, fact also highly supported by the great amount of conceptual papers $(\S 1)$. The ensemble of papers shows that whilst generalized theories can be established, there is also a high degree of contextspecificity in optimal solutions in different circumstances. We argue that broader-scope research (including development of new concepts and frameworks) needs to be integrated with targeted scientific research to promote sustainable agricultural practices, ensure food security and decrease hunger and poverty.

\section{AUTHOR CONTRIBUTIONS}

All authors listed have made a substantial, direct and intellectual contribution to the work, and approved it for publication.

Tilman, D., Cassman, K. G., Matson, P. A., Naylor, R., and Polasky, S. (2002). Agricultural sustainability and intensive production practices. Nature 418, 671-677. doi: 10.1038/nature01014

Tscharntke, T., Klein, A. M., Kruess, A., Steffan-Dewenter, I., and Thies, C. (2005). Landscape perspectives on agricultural intensification and biodiversity - ecosystem service management. Ecol. Let. 8, 857-874. doi: 10.1111/j.1461-0248.2005.00782.x

Tsiafouli, M. A., Thébault, E., Sgardelis, S. P., de Ruiter, P. C., van der Putten, W. H., Birkhofer, K., et al. (2015). Intensive agriculture reduces soil biodiversity across Europe. Glob. Change Biol. 21, 973-985. doi: 10.1111/gcb. 12752

UN-DESA/DSD (2014). United Nations Sustainable Development Goal 2: end Hunger, Achieve Food Security and Improved Nutrition and Promote Sustainable Agriculture. Available online at: https://sustainabledevelopment.un.org/?page= view\&nr $=164 \&$ type $=230$

Vico, G., Manzoni, S., Nkurunziza, L., Murphy, K., and Weih, M. (2016). Tradeoffs between seed output and life span - a quantitative comparison of traits between annual and perennial congeneric species. New Phytol. 209, 104-114. doi: $10.1111 /$ nph.13574

Wang, H., and Swallow, B. M. (2016). Optimizing expenditures for agricultural land conservation: spatially-explicit estimation of benefits, budgets, costs and targets. Land Use Policy 59, 272-283. doi: 10.1016/j.landusepol.2016. 07.037

Zhang, W., Ricketts, T. H., Kremen, C., Carney, K., and Swinton, S. M. (2007). Ecosystem services and dis-services to agriculture. Ecol. Econ. 64, 253-260. doi: 10.1016/j.ecolecon.2007.02.024

Conflict of Interest Statement: The authors declare that the research was conducted in the absence of any commercial or financial relationships that could be construed as a potential conflict of interest.

Copyright (c) 2017 Tsiafouli, Drakou, Orgiazzi, Hedlund and Ritz. This is an openaccess article distributed under the terms of the Creative Commons Attribution License (CC BY). The use, distribution or reproduction in other forums is permitted, provided the original author(s) or licensor are credited and that the original publication in this journal is cited, in accordance with accepted academic practice. No use, distribution or reproduction is permitted which does not comply with these terms. 